\title{
Changing crops in response to climate: virtual Nang Rong, Thailand in an agent based simulation
}

\author{
George P. Malanson ${ }^{a}$, Ashton M. Verdery ${ }^{b, c}$, Stephen J. Walsh ${ }^{b, d}$, Yothin Sawangdee ${ }^{e}$, \\ Benjamin W. Heumann ${ }^{f}$, Philip M. McDaniel ${ }^{g}$, Brian G. Frizzelle ${ }^{b}$, Nathalie E. Williams ${ }^{h, i}$, \\ Xiaozheng Yaoj, Barbara Entwisle ${ }^{b, c}$, and Ronald R. Rindfuss ${ }^{b, c}$
}

aDepartment of Geographical \& Sustainability Sciences, University of lowa, lowa City, IA, USA ${ }^{b}$ Carolina Population Center, University of North Carolina at Chapel Hill, Chapel Hill, NC, USA 'Department of Sociology, University of North Carolina at Chapel Hill, Chapel Hill, NC, USA ${ }^{d}$ Department of Geography, University of North Carolina at Chapel Hill, Chapel Hill, NC, USA eInstitute for Social and Population Research, Mahidol University, Bangkok, Thailand fDepartment of Geography, Central Michigan University, Mount Pleasant, MI, USA 9Davis Library, University of North Carolina at Chapel Hill, Chapel Hill, NC, USA hJackson School of International Studies, University of Washington, Seattle, WA, USA 'Department of Sociology, University of Washington, Seattle, WA, USA 'Center for Natural Resources Assessment and Decision Support, Virginia Tech, Blacksburg, VA USA

\begin{abstract}
The effects of extended climatic variability on agricultural land use were explored for the type of system found in villages of northeastern Thailand. An agent based model developed for the Nang Rong district was used to simulate land allotted to jasmine rice, heavy rice, cassava, and sugar cane. The land use choices in the model depended on likely economic outcomes, but included elements of bounded rationality in dependence on household demography. The socioeconomic dynamics are endogenous in the system, and climate changes were added as exogenous drivers. Villages changed their agricultural effort in many different ways. Most villages reduced the amount of land under cultivation, primarily with reduction in jasmine rice, but others did not. The variation in responses to climate change indicates potential sensitivity to initial conditions and path dependence for this type of system. The differences between our virtual villages and the real villages of the region indicate effects of bounded rationality and limits on model applications.
\end{abstract}

\section{Keywords}

agent based model; bounded rationality; climate change; endogenous dynamics; land use change; Thailand

\footnotetext{
(C) 2014 Elsevier Ltd. All rights reserved.
}

Publisher's Disclaimer: This is a PDF file of an unedited manuscript that has been accepted for publication. As a service to our customers we are providing this early version of the manuscript. The manuscript will undergo copyediting, typesetting, and review of the resulting proof before it is published in its final citable form. Please note that during the production process errors may be discovered which could affect the content, and all legal disclaimers that apply to the journal pertain. 


\section{Introduction}

Agricultural systems are at the center of global change. Agricultural systems lead to extensive change in land cover, are the locus of increasing human appropriation of net primary productivity (Haberl et al. 2007), and are directly affected by climate change. Much of the consideration of agricultural response to climate change is at a scale above that of farmers (Parry et al., 2005), but individual farmers or farm households will be the locus of change. Farmers respond to weather on a short time scale, altering their timing of planting, harvesting, and other activities day-to-day and potentially changing crops seasonally. And while land use decisions by farmers are embedded in a larger framework of the economy and society in which the farmers operate, each farmer or farm household has an individual locus within this framework, and responses to changes, such as climate change, can vary. The characteristics of the farm household itself also vary and interact with other components in important ways, and households are now the common focus for studies of land use decision-making. But the individual households may be linked in social and economic networks, and villages are important structures in this framework. In this research we consider environment and demography in the kind of agricultural economy found in northeastern Thailand. We use an agent based model (ABM) and ask whether we can gain insights into the land use decisions in this type of place by examining relations in a virtual environment. The role of such models in a system with bounded rationality is assessed through examination of the differences between virtual and real villages.

\subsection{Background}

One approach for including individual farmers or households is in individual-based simulation models. Hagerstrand (1966) developed the first such model for farming decisions. Parker et al. (2003) developed a rationale for using Multi-Agent System (MAS) models (aka Agent-Based Models, ABM) for the study of land use change. They noted that MAS can address spatial heterogeneity and effects in a system of distributed, but interdependent and hierarchical, decision making. MAS harness increased computational power so that individuals can be represented in detail, but they are essentially the same model concept introduced to geography by Hagerstrand (1966), who simulated the diffusion of adoptions in agriculture. While Parker et al. (2003) noted several applications of agent models being used at the time, several groups and individuals have developed more advanced models in the subsequent decade. Those that address agricultural land use and farm households vary in many details. The balance of drivers and constraints vary among economics, environment, and demography but all include feedbacks among the land uses and household socioeconomic variables. The degree to which decision making is patterns are grouped into 'types' of households also varies (Sengupta et al. 2005, Bakker et al. 2009, Mialhe et al. 2012).

The uses of MAS or ABM in land use studies were reviewed again by Matthews et al. (2007). Given the eruption of modeling, they described five categories of modeling, but the categories mix methods and aims. The interesting method is participatory modeling, in which the subjects of the study help build the model to some degree, better defining the processes of decision-making (e.g., d'Aquino et al. 2003, Etienne et al. 2003). Their

Appl Geogr. Author manuscript; available in PMC 2015 September 01. 
categories of social and economic concepts and policy and planning overlap, because some policies are hypothetical. In policy analysis and planning, Janssen (2000), Deffuant et al. (2002) and Sengupta et al. (2005) addressed decision making in response to environmental quality related policies, while Evans and Kelley (2004), Deadman et al. (2004), and Manson et al. (2005) addressed similar decisions without a specific policy framework. An et al. (2005) and Matthews (2006) incorporated more biophysical aspects in their models. Becu et al. (2003) simulated basic choices of crops in a Thai setting constrained by cash, labor, and water; their approach is a starting point for this study.

Since Matthews et al.'s (2007) review, decision making by agriculturalists often has been modeled using MAS/ABM in the context of "frontier" locales (Rindfuss et al. 2007) where deforestation is a primary process (Moreno et al. 2007, Manson and Evans 2007, Kelly and Evans 2011). Much of this work is about farm vs. forest decisions (e.g., Deadman et al. 2004), while some differentiate farming choices (Manson 2005). While our modeling is not about deforestation (although deforestation occurred in our area in the recent past), the increasing focus on household decision-making with details of household demographics making a difference (Mena et al. 2011) are a further basis for our work.

Some agent based models have been developed specifically for examining the response of societies, including agricultural ones, to climate factors. Moss et al. (2001) argued that agent based models were appropriate for integrated assessment of climate change implications because they take actors at different hierarchical levels into account. They further note that sociological models for decision processes are not predictive, but are well suited to counterfactual experiments, what-if analyses, and policy discussion. Patt and Siebenhuner (2005) encouraged agent based modeling for adaptation to climate change because new solutions could emerge where many agents faced the same problem. Angus et al. (2009) designed an agent model for a purpose (i.e., climate change and agricultural response in Bangladesh) similar to ours, but while they included a broader context they did not discuss the details of implementation. Mialhe et al. (2012) examined a similar type of environmental change, delta subsidence, and its effect on farming decisions in the Philippines, finding different responses among categories of agents. Schluter and Pahl-Wostl (2007) used ABMs to assess river management as resources become limited. Patt and Siebenhuner (2005) discussed the issues facing the use of ABM for adaptations to climate change. In more specific situations, Ziervogel et al. (2005) looked at responses to climate forecasts, and Angus et al. (2009) developed a coarse-scale agent model to examine economic, migration and mortality in Bangladesh in response to climate change. While all support the general intent for using $\mathrm{ABM}$, none approach the level of spatial and social resolution that we attempt.

The system most similar to ours was modeled by Naivinit et al. (2010). Using an agent based model for rice farming and migration in northeastern Thailand. While their model was developed to enhance communication between farmers and researchers, it includes more detailed steps in rice growing but less environmental and demographic variability than our approach. Their model stimulated co-learning opportunities in the village and enhanced preparedness for droughts. 
Our basic theory for land use decision making in an agent model framework, derived from bounded rationality, is from Pred and Kibel (1970), who included crop changes in their concept set. They presented a behavioral matrix of two dimensions: information and ability to use that information, with perfect knowledge and ability ("economic man") at one corner and randomness at its opposite. However, locating any agent between the extremes in this matrix is problematic; Pred and Kibel (1970) noted three aspects of complexity: three types of growth or change are found (in states (area of crops); in agents (number of households); in relations (feedbacks from past outcomes affect decisions)); and three events occur (new behaviors by agents; loss of agents or decisions; repetition of decisions). While Pred and Kibel (1970) noted that their simulation board game led to data that was voluminous but too fragmented for derivation of general behaviors, they believed that a computer simulation would be profitable. However, narrowing the decision framework for any agent still is difficult to theorize. Complexity theory, a loosely defined body of theory about multidimensional systems developing from fewer rules, has also been called upon for support in land use change literature (e.g., Parker et al., 2002; An et al., 2005; Walsh et al., 2008; Mena et al., 2011). Complexity theory indicates that in the two dimensions discussed by Pred and Kibel (1970) the location of a decision maker and decision could be defined, but only imprecisely (cf. Malanson et al., 2006a,b). An (2012) noted the connection between complexity theory and the modeling methods for coupled human-natural systems. Manson (2006) used an ABM for land use in the Yucatan to explore programming options to capture bounded rationality that we assume; he noted the still-weak state of theory in this area.

\subsection{Location and rationale}

The overall objective of this paper is to understand how agricultural land use changes in response to different climate perturbations across a range of environmental and social conditions in a system representing a rural area increasingly connected to global forces. We use an agent-based model to address this objective. Because system-level changes may be influenced by individual-level decision-making, ABM is an appropriate method. However, complexity theory indicates that model behavior will be sensitive to individual-level parameterization, and will provide information on the type of system on broad constraints for a particular system (Manson 2001, 2007; Malanson et al. 2006a,b). Even the most wellparameterized ABMs assess either system level results or more contrasting land uses than agricultural choices (e.g., An et al. 2005). In our case, individual-level parameterization is detailed, but how it affects decisions is unknown; therefore we do not model a specific, real place with expectations that we can predict or even postdict its land use dynamics. Instead we model a "virtual' region in order to draw lessons about how a model can elucidate land use change processes, but we also examine the limits of such models to do so. In this way we are able to evaluate the effects of bounded rationality by focusing on system behavior with some insights from comparison with particular real villages - but we do not intend to simulate real village dynamics. We are interested in how the endogenous dynamics (the socioeconomics) of a complex system respond to simple exogenous forces (climate variability), whereas in the real Thailand exogenous socioeconomic forces are important. This work is in contrast to, and may indicate the limitations for convergence with, empirical work on similar land use change (e.g., Castella et al. 2005, Chau et al. 2013, Vongvisouk et al. 2014

Appl Geogr. Author manuscript; available in PMC 2015 September 01. 
We address the following questions:

1) How does land use change with a climate perturbation? Are changes sudden or gradual?

2) Are the modeled land use changes associated with environmental or social initial conditions?

3) Does climate perturbation have a lasting effect on land use?

4) How do the outcomes in virtual Nang Rong compare to our understanding of the real Nang Rong?

We base our virtual region on the Nang Rong District, Buriram Province, northeastern Thailand (Figure 1) using the geography as it existed c. 1984 (the time of our original survey; it has since been subdivided). That Nang Rong occupies c. $1300 \mathrm{~km}^{2}$ with a population in 2005 of c. 170,000. The land is generally flat, with a south-north slope of $<1 \%$ (excluding the volcanic remnants), with upland crops such as cassava dominating in the southwest and rice paddy in the center and north; however, local small variations in topography alter soils and suitability for crops. The region is generally marginal for agriculture in comparison to Thailand's central valley, with low soil fertility and inconsistent monsoons (Rigg 1985). The region is extensively farmed, however. Although the area was occupied in the Khmer period (c. 800-1400 AD; some remnant features outline a few current villages), the district had $\sim 22$ villages in 1900 and 83 in 1950, but increased to $>350$ by 2000. Villages sometimes split into two administrative villages when the number of households reaches $\sim 200$, and so some village pairs or triplets are contiguous (the pattern is centralized dwelling spaces surrounded by farmland, not farm households scattered on their land) (Entwisle et al. 2005, 2008a). Prior to 1970 occupancy was in the lowlands and land use was primarily rice farming. Following the development of a European market for cassava and other aspects of globalization, the uplands in the south of the district were developed for cassava and more recently for rubber (Tang et al. 2009). Sugar cane, kenaf, and fruit trees are also found.

Our interest in the problem is driven by a broad question of why villages would differ in this type of system. Thirty years ago, when members of our team first began formal study in our area (one having been born and raised there decades earlier), villages were more similar than they are now: the villagers were poor, limited in education and any infrastructure (e.g., running water), and almost entirely engaged in subsistence agriculture; differences included proximity to paved roads and electricity. While all villages now have some improved infrastructure and access to schools and have at least minimal ties to wider markets, some are very similar in physical appearance what they were 30 years in the past, while some others have modern, western-style houses. The social structure in both extremes have changed, with the core working age cohort often missing - but at factories or construction labor in Bangkok and the eastern seaboard in the former case versus white-collar employment there.

Although we are interested in the people of Nang Rong, we use an ABM created for the district to simulate the land use change for 41 virtual villages; our model does not make 
predictions for the people of Nang Rong. Our ABM is designed to take advantage of detailed demographic data linked to land use from 51 villages ( 10 had missing data and were not used), but the model is not about these villages per se (although knowledge of the villages may help interpret the model rather than vice-versa); thus we do not provide detailed information on them (as well as to protect their privacy). This linkage was described by Walsh et al. (2013), discussed below. The details of demographic relations developed from studies of family planning (e.g., Entwisle et al. 1984), but expanded to broader socioeconomic concerns (Faust et al. 1999). An important result was the link established between rural-urban migration and land use (VanWey 2003). Basic data on land use patterns was developed using remote sensing and geographic information systems (Walsh et al. 1999, 2001, Crews-Meyer 2002, Welsh 2008). Concepts of the link between land use and households were established that emphasized demography (Walsh et al. 1999, Entwisle et al. 2005,2008 b). These studies provide the basis for the approach used here.

We ran the $\mathrm{ABM}$ as an experimental environment. The runs are for 41 villages, over 25 years iterating annually, and with 40 replications based on the same 40 random number seeds used for all villages. Twenty-five years is sufficient to see some of the dynamics of this type of system, but the likelihood of disruption by exogenous forces in even this period is one reason why we model a virtual Nang Rong without intent to represent the actual villages. We used a control scenario of a constant moderate climate and treatments of different climate scenarios (more below). We analyzed the outcomes of the simulation by visually examining the average trajectories of land use across all villages and for each village individually. To illustrate outcomes, we discuss particular virtual villages in relation to their actual counterparts.

\section{Methods}

\subsection{Agent based model}

Entwisle et al. (2008a) described the general structure of our model, and Walsh et al. (2013) provided detailed description of the structure of the land use component of the model. We do not duplicate these descriptions here, but we summarize the aspects that are relevant for the questions of response to climate change. The land use decisions are made by each household in a village, and the attributes of the household in a hierarchy as shown in Table 1. We designed the model to take advantage of the extensive socio-demographic survey data available; these data are available for public and restricted use through http:// www.cpc.unc.edu/projects/nangrong/index.html. The social component of the model makes most use of these data, and includes processes of birth, death, marriage, and migration with links to social networks, economics and information flows. These factors, while in the background of this study, are linked to land use choice because agricultural activity depends on labor and agricultural output contributes to household assets, which affect other processes. In terms of the categories defined by An (2012) in a review of approaches in agent based modeling, our model combines aspects of his empirical and microeconomic categories.

The land use change decision in the ABM has five alternatives: jasmine rice, heavy rice, cassava, sugar cane, and unused-by-village. Jasmine is represented in the model by 
KDML-105 (khao dak ma li), the most popular cultivar in the region, which was developed as a commercial product. Heavy rice (khao nak) is a variety of jasmine but not the popular one; it is a local, less developed cultivar primarily known for its ability to grown in wet conditions and to produce a crop when planted late in the year (Curran and Sawangdee 1998). Cassava is an upland root crop, and the development of an export market led to the settlement of higher lands in Nang Rong (Entwisle et al. 2008a). Sugar cane is the world's most extensively cultivated crop (FAO 2013; http://faostat.fao.org/site/339/default.aspx), which speaks to the broad adaptability of the genus. The initial crop choices are assigned using a MaxEnt model to generalize observed land use (Heumann et al., 2011, 2013). Crop yields for the 37 soils identified in the district are based on simulations using DSSAT v4 (Jones et al. 2003) for different scenarios of weather patterns and household ability to use fertilizer. The unused-by-village land use is the difference in the amount of land used for the four crops in any year and the maximum area used throughout the simulation for that village and within that simulation repetition. This category represents land that could be used but is not yet in use or is no longer being used, depending on when farming is most extensive. When not in use this land could be fallow (although villagers claim they do not let land lie fallow), yet to be cleared of trees, or in use by another village; our simulation does not distinguish these alternatives and the focus is on how much land is being farmed by the households in a village as their socioeconomic circumstances change.

The primary basis for change in a given year is the expected income from the given crops, given their yields and prices, but constrained by labor, assets, and a threshold of willingness to change. Assets change with crop productivity and also, possibly, with remittances from migrants in the household, but migrants can lead to a labor shortage and less land farmed.

\subsection{Climate change}

Extension of weather scenarios, as described by Walsh et al. (2013), is the functional core of the problem addressed here. The weather can follow a variety of scenarios, but is based on the nine combinations of timing and amount ([early, normal, late] and [low, normal, high]) of monsoon precipitation. These nine scenarios are based on data on actual monthly rainfall in Nang Rong from 1900-2008, accessed from the University of Delaware Center for Climate and Land Surface Change (http://climate.geog.udel.edu/ climate/html_pages/ archive.html\#gcd), with years of climate divided among within vs. beyond $+/-$ one standard deviation of the mean start of the monsoon and amount of precipitation. Normal-normal weather has the timing and amount of precipitation that approximates the mean for the 1900-2008 period; wet-early weather is one standard deviation wetter (which coincides with earlier) and dry-late is one standard deviation drier (and later). We developed seven new climate scenarios, four of which we use here. The normal X normal scenario is our experimental control, wherein we maintain this constant weather for 25 years. The alternate scenarios are for extreme drier, wetter, and variable weather. To simulate extreme weather, in years 11-17 the weather changes from normal-normal to dry-late (extreme drought), to wet-early (extreme flood), to a 2-yr cycle of dry-late and wet-early (extreme variability); in these cases the weather returns to normal-normal for the following 8 years. Last, we also ran the model with the climate sequence observed for 1975-2000. 


\subsection{Household and village levels}

The model is initialized for the households recorded through intensive surveys in 41 villages in 1984, 1994, and 2000 across Nang Rong District. Given the land use decision-making at the household level, we present results at the village level because it is appropriate to discuss the meaning of the outcomes at the higher hierarchical level, i.e. villages. In this contention we follow well-developed ecological theory regarding hierarchies (Allen and Starr 1988).

The primary output of our model is the area each village devotes to each land cover in each year. We examine this absolute area and the difference in area from the control (normalnormal) climate relative to the maximum area farmed for all four crop types in any year. We also track the total amount of land being used by each village, and we consider the difference between the largest area used by a village in any year and the area in other years.

We focus on the village-level results for decisions made at the household level. Illustrating trajectories of land use change for single villages is informative, because aggregation can mask processes and the contrasts become evident. Thus in our results we first present the land uses averaged across all villages for the period of the simulation and then we use individual villages for illustration of divergent patterns.

\section{Analyses and Results}

We first present the areas devoted to the four crops in the control climate and the actual sequence of climates for the years 1975-2000, and then the difference between the control and the other climate scenarios, for the virtual Nang Rong district as the average from our 41 villages and 40 replicate simulation runs. The control climate, normal-normal, results in a stable proportion of crops with a general increase in jasmine rice. The same is true for a simulation of the actual sequence of climate in the simulation years. Our terminology is as follows:

C1: Climate1, control, normal-normal

C2: Climate2, extreme flood

C3: Climate3, extreme drought

C6: Climate6, extreme variability

Ab: Absolute area in a crop

Df: Difference in $\mathrm{Ab}$ from $\mathrm{C} 1$

$\mathrm{Rd}$ : Df relative to area farmed by village

For example, the relative difference in crops from the control climate for the simulation for extreme drought is $\mathrm{C} 3 \mathrm{Rd}$.

\subsection{Trajectories averaged across villages}

We begin with the mean area farmed across all villages for the control climate and for the observed 1975-2000 climate (Figure 2). Jasmine rice is the dominant crop, but declines in average area throughout the simulation. Land not in use increases.

Appl Geogr. Author manuscript; available in PMC 2015 September 01. 
The simulation results averaged across all villages for the differences in the climatic scenarios versus a steady normal-normal climate are shown in Figure 3, a-f. With Climate2, extreme flood, the changes are relatively small. The amount of land in jasmine rice drops as land is switched to heavy rice, but jasmine recovers while the drought persists. Cassava drops and does not recover until after the drought abates. Heavy rice, gaining at first, shows some volatility and then recedes after the drought passes. Sugarcane increases more or less consistently through and following the drought. With scenario 3, extreme drought, the pattern of change is more definitive. Jasmine rice area drops consistently until after the drought ends. It is replaced quickly by sugarcane and slowly but steadily by heavy rice. Cassava sees a consistent but slight decline. With extreme variability (scenario 6) the change is somewhat similar to extreme drought, but jasmine declines even more abruptly while the increases in sugarcane and heavy rice are more similar and gradual.

Across all villages, the most consistent result is that extreme weather leads to volatility in land devoted to jasmine rice. However, this is not the only response and the degrees of change differ. In absolute terms, those villages with larger amounts of land under cultivation shift more of that land, but in relative terms they change less.

\subsection{Reduced crop outcomes}

We analyzed the changes in the climate scenarios in individual villages. To illustrate change we chose villages based on nonmetric multidimensional scaling (NMDS) analyses and visual assessment of all crop trajectories of all villages. In separate NMDS analyses we use the three measures of crop outcomes, $\mathrm{Ab}, \mathrm{Df}$, and $\mathrm{Rd}$, in the three climate scenarios $(\mathrm{C} 2, \mathrm{C} 3$, C6), but here we average these across the 40 simulation repetitions at year 25 of the runs (i.e., 9 model outcomes are ordinated). For the distance measure in NMDS we use the simple Euclidean distance, because we have negative and positive numbers and Euclidean distance in a 4D space (from four crops) involves no assumptions. All NMDS ordinations had stress $<10$. The most notable initial result was that village A was an outlier in most ordinations (Figure 4).

Although the trend across all villages is for a decrease in jasmine rice and an increase in sugar, individual villages have all possible combinations of increases and decreases in the four crops. The locations of villages in the ordination spaces help to identify ones that represent different types of outcomes. The trajectories for all land uses in all villages, as shown in Figures 5-9 but for 5 land uses and all 41 villages, complemented these patterns. From the ordinations and trajectories, we chose villages B, C, D, E, F, and return to A to illustrate common trends.

\subsection{Contrasting changes in land use, villages}

Village B shows abrupt and definitive increases in heavy rice for extreme flood and variability (and in sugar for extreme drought and variability) (Figure 5). These are at the expense of land in cassava and jasmine rice, respectively. Village B is in an area of generally poor soils toward the southwest of the study area, but occupies an island of higher productivity with the same pattern for rice, cassava and sugar.

Appl Geogr. Author manuscript; available in PMC 2015 September 01. 
Village $\mathrm{C}$ is notable because it is not greatly affected by climate change (e.g., Figure 6). Its land uses are similar to those of the normal-normal climate in cases of extreme flood, drought, and variability. Village $\mathrm{C}$ is in land well-suited for rice near the center of the study region.

Village D responds to flood and drought similarly, with declines in cassava and an expansion of sugar, some increase in heavy rice, and decrease in jasmine rice (e.g., Figure 7). These appear to be direct switches in amounts in these pairs. Village D is located toward the south of the study area in lands well-suited for cassava but with potential for sugar and rice as well.

Village E illustrates an increase in sugar cane, already relatively high, with climate change, particularly with increasing drought (Figure 8). This increase, along with modest increases for heavy rice, come at the relative expense of jasmine rice, but village $E$ is one that expands its use of farm land.

Many villages had less abrupt change, and village F, near the center of the ordination space (Figure 4), can be shown as an example. While sugar still has a notable increase in extreme drought and variability relative to the control climate, the increase in heavy rice and the decreases in jasmine rice and cassava are modest in all three extreme climate scenarios. Here we illustrate the typical trend for land not in use by this village (Figure 9). Village F is located near the center of the area and is surrounded by good soils for rice and sugar while the soils for cassava are poor with some good patches.

Village A most differed from others because it had a strong increase in cassava in absolute amount and relative to the control climate, especially in extreme flood and variability scenarios (Figure 10). It was the only village that had such a pattern.

\subsection{Contrasting changes in land use, crops}

Jasmine rice-After any of the climate changes, most villages have a steady decline in area in jasmine rice, similar to the control (normal-normal) climate. Village $\mathrm{C}$ has a decline, especially for extreme drought and variability. Village B changes away from jasmine abruptly for extreme drought and variability but not flood. While most villages decline in jasmine as does the control, some have a level response also close to but below the control. A few villages (e.g., A, B, C) have an abrupt decline in jasmine as soon as the climate changes - none more abrupt that village A (Figure 11).

Heavy rice-Most villages have a decline in Heavy rice similar to the control, with some relative increases with flooding or variability but rarely far from the control amount. In village A, extreme flood leads to higher heavy rice for a few years (as noted above, heavy rice can produce a crop in the shorter growing season following flooding). Villages B and C show an abrupt increase in heavy rice for extreme flood and extreme variability, and while it begins to decline, it is still much above the control by the end of the simulation period.

Cassava-Following climate change, almost all villages have the same cassava as in the control. Most of these show a steady decline, starting after $\sim 5$ years of increase (i.e., 
beginning before climate change). A few show abrupt drops in cassava land immediately following climate change (B, C, E); these excursions are for extreme drought and variability, not extreme flood. Village A is the only one to show an increase in cassava. For extreme drought it increases slightly, but for extreme flood and variability there is an abrupt increase in cassava that is maintained through the simulation period. Increasing cassava is what makes this village unique.

Sugar-Almost all villages show an abrupt and strong increase in sugar following climate change that is maintained until the end of the simulation period. Where more land that was in sugar at the beginning of the simulation, the amount of increase is greater: villages that had good land for sugar increase their effort in that crop (B, C) but high relative changes are seen widely.

Not used (yet-to-be or no-longer used). In the simulation, whether and how much a household chooses to farm is a crucial decision point. Households can expand their agricultural lands or not use them. One of the primary differences that we see is in the trend in amount of land farmed. In the simulation, $75 \%$ of villages reduced agricultural land use (often after an initial 5 year increase) while the other $25 \%$ increased farmed land. No villages maintain the same area for farming. Notably, no village showed a difference in amount of land used between the control scenario and any climate change scenario; this result held for the scenarios of more extreme climate change that we do not report extensively here. The 11 villages that expanded agricultural land use are scattered from the far north to the east, southwest and southeast. With the exception of village A in the middle, the others are spatially associated in pairs with their nearest neighbor. These pairs may indicate an underlying pattern such as soil diversity.

\section{Discussion}

\subsection{Patterns of individual crops}

The difference between jasmine rice and sugar is notable from an agronomic or plant ecological perspective. Plant ecologists array species on a gradient of specialization. Specialized species tend to be most productive but only in a narrow range of environmental conditions while generalists are less productive but still produce across a wider range; the gradient is the result of evolutionary trade-offs and locus of a species on the gradient is a product of the combination of spatial and temporal gradients in the environment over evolutionary time. Jasmine rice, and KDML-105 in particular, is a specialist given the human-controlled evolutionary conditions that produced it. Sugar cane, while specialized in some cases, is more of a generalist and a specific cultivar for northeast Thailand has not been developed. The response of virtual Nang Rong farmers to climatic extremes can be interpreted as an ecological response to a changing niche. Hudson (1967) first connected land use to ecological niche theory in geography. When conditions become less predictable, crops that can provide returns in a wider variety of conditions are more dependable and provide better support for a family, even if their market price is substantially lower (for reference, Nang Rong villagers say that they save $250 \mathrm{~kg}$ per person per year for household consumption; the current price of jasmine rice is c. $\$ 1100$ per tonne). 


\subsection{Responses to climate scenarios}

Flood vs. Drought. In our simulations drought had greater effects than did flooding. This result aligns with the general sense communicated by villagers in Nang Rong that droughts were more problematic than floods - although both were identified as the worst of two evils, either in different villages or by different people in the same village. In neither case did we simulate a condition in which a climate change resulted in no agricultural production in a given year; all effects were on change in productivity based on time of planting and water availability.

\subsection{Village $A$}

Although its land use choices are in contrast to others, virtual village A may be informative and may link virtual Nang Rong in the ABM to the people in Thailand. Village A was one that we visited as a team in 2010. It was the one we identified as being among the least developed and least changed in physical structure in recent decades. It also had an interesting social structure.

We visited this village because we thought they were participating in the expansion of rubber in the district, but the villagers told us that nearby rubber areas belonged to someone from Nang Rong Town. They identified themselves as rice farmers; they came to Nang Rong and cleared the forest for that purpose. However, their productivity is relatively low (1/3-1 sack / rai, compared to 5-8 reported by other villages), they do not have the technology to irrigate from the nearby canal when needed, and other crops are marginal (eucalypts) or failed (papaya). No one attempts cassava or sugar cane. Village A may be in an unusual location. It is near the center of the district in the heart of the rice growing area. However, in part it occupies a sliver of land that the soil maps indicate is better for cassava. This difference in soil is why virtual village A exhibits the unique change away from rice toward cassava, and why it expands its use of land for farming, in our simulations. It may also be why the real village reports relatively low productivity for rice and why it is apparently less wealthy than the others, indicating less than perfect knowledge.

Although not unique, real village A seemed to stand out in the demographic structure that it represents. The village was occupied by children and their grandparents and greatgrandparents. The "parent' generation was working in Bangkok in non-agricultural sectors. These villagers were vocal about their situation. They feel that they have become "servants of their children" (the parent generation) who leave the youngest with them when they migrate. When asked about remittances from their migrant children, when one started a positive reply, another spoke up: "Must be somebody else's!" (cf. Piotrowski 2009, who reported that households with migrant "skipped" generations are likely to receive lower but more dependable remittances from those migrants). As in the models, migration is an important factor - but migration does not always mean the same thing among different villages or even among households within villages (Piotrowski 2009, Piotrowski and Tong 2010, Rindfuss et al., 2012). The status of the village and these comments indicate that the social fabric is strained by migration.

Appl Geogr. Author manuscript; available in PMC 2015 September 01. 


\section{Conclusions}

\subsection{Virtual Nang Rong}

Comparisons between virtual Nang Rong and the villages and households we encounter there provide some insight into the role of landscape and society in land use in scenarios of climate change. Insights (and more questions) are generated in the patterns of responses in different areas of Nang Rong and in different social arrangements among villages. Overall weak statistical relations limit inference, however.

The overall landscape and pattern of soils plays a role in village response to climate change. Some villages are on better land for any kind of agriculture and so are better buffered against the impacts of climate. These villages respond to the population processes in the model and differ little from the control climate scenario. Some villages have a mix of soils in their neighborhood, which gives them flexibility to change crops. In all cases the climate returns to the control conditions in the last 8 years of the simulation and land uses begin a trajectory toward pre-perturbations conditions. Virtual Nang Rong appears to be endogenously resilient to the perturbations introduced in this study, but we have not included the likely exogenous forces that might accompany extended climate change (or those that are always prominent in the real economy). Since the base period for our model the government of Thailand has intervened in the rice market, and now has plans to address climate change (http://www.onep.go.th/).

\subsection{Agent Based Models}

ABMs generate alternatives. As noted by Moss et al. (2001), counter-factual experiments, represented by our climate scenarios, provide insights into what processes are involved in land use change. The differences between the control climate and those of climate change illustrate interactions between land use decisions and other socioeconomic processes. ABMs are suited to analysis of interactions because they incorporate endogeneity in the iterations. As Patt and Siebenhuner (2005) and Mialhe et al. (2012) noted for many agents or categories of agents, our analysis shows that many villages can produce alternative responses to the same problems, based in part on their agronomic environment and in part on their socioeconomic characteristics. ABMs produce varied outcomes within as well as among villages, and illustrate that any outcome is one of a range of possibilities. The results for village A show that information from the real Nang Rong may inform the modeled virtual Nang Rong better than vice versa.

\subsection{Bounded rationality and complexity theory}

Virtual Nang Rong illustrates the use of ABMs as informed by bounded rationality and complexity theory. The ABM uses a combination of empirical and theoretical relations. This combination is designed to limit the uncertainty about the location of any decision maker or decision in Pred and Kibel's (1970) decision space. From analyses not reported here, the initial conditions of our socioeconomic inputs are weakly correlated with land use outcomes; the processes of interaction through time and space create the outcomes, illustrating the need for simulation as argued by Pred and Kibel (1970). However, we may not be specifying the information or rationality of the decision makers closely enough. For example, the 
difference between the virtual and observed village A, where the former adopts more cassava while the latter identifies itself as a rice village, indicates how even a betterspecified area in the decision space in the model may not match that of the people in the observed village. Further, the use of ABMs to extend empirical work, such as that of Chau et al. (2013) on effects of flooding on crops in Vietnam, may be limited because of their sensitivity to this uncertainty. Given the level of demographic and environmental detail in the model and the computational resources in design and execution, the inability to meet Pred and Kibel's (1970) expectations of better specification through computation is exasperating. However, complexity theory may provide another interpretation.

Complexity theory, as variously interpreted in geography (e.g., Malanson, 1999; Manson, 2001; Walsh et al. 2008), has opposed components of sensitivity to initial conditions (Malanson et al., 1990; Phillips, 1994; Manson, 2007) and self-organization (Haken and Portugali, 1995; Malanson et al., 2006b). Agent based models are, in theory, able to incorporate the variations to which complex systems are sensitive, but then require precision in the specification of the characteristics of individuals. For example, earlier demographic research in Nang Rong found that villages differed in choice of contraceptive method based on whatever choice the first adopter in the village made. Self-organization, wherein systems with many dimensions (e.g., decision makers) have structures (e.g., land use patterns) in a few dimensions, can limit the range of outcomes based on imprecision in initial specifications, thus creating path dependence (Brown et al., 2005). Thus even having decision makers well but imperfectly specified by our socioeconomic variables could result in divergence in land use from similar but not identical initial conditions - and thus low correlations in our analyses. Self-organization could limit the divergence, but would be difficult to identify over the short course of the simulation period (over longer periods exogenous forces are likely to overwhelm any self-organization); moreover, the organization may be in dimensions other than land use. The weak statistical outcome reinforces the lessons of complexity theory (Manson, 2007), making specific policy or planning directives difficult.

\section{Acknowledgments}

This study was funded by grants from the NSF (BCS 0728822) and the NIH (R21 HD051776 and R21 ES016729) to Barbara Entwisle, PI. For various input and assistance, we thank Peter Mucha, Deng Ding, Aree Jampaklay, and especially Pramote Prasartkul and the staff of the Institute for Population and Social Research at Mahidol University.

\section{References}

Allen, TFH.; Starr, TB. Hierarchy. University of Chicago Press; Chicago: 1982.

Angus, SD.; Parris, B.; Hassani, MB. Climate change impacts and adaptation in Bangladesh; An agentbased approach. 18th World IMACS/MODSIM Congress; 2009. http://mssanz.org.au/modsim09

An L. Modeling human decisions in coupled human and natural systems: Review of agent-based models. Ecological Modelling. 2012; 229:25-36.

An L, Linderman M, Qi J, Shortridge A, Liu J. Exploring complexity in a human-environment systems: an agent based spatial model for multidisciplinary and multiscale integration. Annals of the Association of American Geographers. 2005; 95:54-79.

Bakker MM, van Doorn AM. Farmer-specific relationships between land use change and landscape factors: Introducing agents in empirical land use modeling. Land Use Policy. 2009; 26:809-817. 
Becu N, Perez P, Walker A, Barreteau O, Le Page C. Agent based simulation of a small catchment water management in northern Thailand Description of the CATCHSCAPE model. Ecological Modelling. 2003; 170:319-331.

Brown DG, Page S, Riolo R, Zellner M, Rand W. Path dependence and the validation of agent-based spatial models of land use. International Journal of Geographical Information Science. 2005; 19:153-174.

Castella JC, manh PH, Kam SP, Villano L, Tronche NR. Analysis of village accessibility and its impact on land use dynamics in a mountainous province of northern Vietnam. Applied Geography. $2005 ; 25: 308-326$.

Chau VN, Holland J, Cassells S, Tuohy M. Using GIS to map impacts upon agriculture from extreme floods in Vietnam. Applied Geography. 2013; 41:65-74.

Curran, S.; Sawangdee, Y. Demographic and environmental factors affecting agricultural decisionmaking. Unpublished fieldwork report, Institute for Population and Social Research, Mahidol University and Carolina Population Center, University of North Carolina; 1998.

D'Aquino P, LePage C, Bousquet F, Gah A. Using self-designed role-playing games and a multi-agent system to empower a local decision-making process for land use management: The SelfCormas experiment in Senegal. JASS-The journal of Artificial Societies and Social Simulation. 2003; 6 \#3.

Deadman P, Robinson D, Moran E, Brondizio E. Colonist household decisionmaking and land-use change in the Amazon Rainforest: an agent-based simulation. Environment and Planning B. 2004; 31:693-709.

Crews-Meyer KA. Agricultural landscape change and stability in northeast Thailand: historical patchlevel analysis. Agriculture, Ecosystems \& Environment. 2004; 101:155-169.

Deffuant, G.; Huet, S.; Bousset, JP.; Henriot, J.; Amon, G.; Weisbuch, G. Agent-based simulation of organic farming conversion in Allier department. In: Janssen, MA., editor. Complexity and ecosystem management. Edward Elgar; Northampton, MA: 2002. p. 158-187.

Entwisle B, Hermalin AI, Kamnuansilpa P, Chamratrithirong A. A multilevel model of family planning availability and contraceptive use in rural Thailand. Demography. 1984; 21:559-574. [PubMed: 6519323]

Entwisle B, Malanson GP, Rindfuss RR, Walsh SJ. An agent-based model of household dynamics and land use change. Journal of Land Use Science. 2008a; 3:73-93.

Entwisle B, Rindfuss RR, Walsh SJ, Page PH. Population growth and its spatial distribution as factors in the deforestation of Nang Rong, Thailand. Geoforum. 2008b; 39:879-897.

Entwisle B, Walsh SJ, Rindfuss RR, VanWey LK. Population and upland crop production in Nang Rong, Thailand. Population and Environment. 2005; 26:449-470.

Etienne M, Le Page C, Cohen M. A step-by-step approach to building land management scenarios based on multiple viewpoints on multi-agent system simulations. JASS - The Journal of Artificial Societies and Social Simulation. 2003; 6 \#2.

Evans TP, Kelley H. Multi-scale analysis of a household level agent-based model of landcover change. Environmental Management. 2004; 72:57-72.

Faust K, Entwisle B, Rindfuss RR, Walsh SJ, Sawangdee Y. Spatial arrangement of social and economic networks among villages in Nang Rong District, Thailand. Social Networks. 1999; 21:311-337.

Haberl H, Erb KH, Krausmann F, Gaube V, Bondeau A, Plutzar C, Gingrich S, Lucht W, FischerKowalski M. Quantifying, and mapping the human appropriation of net primary production in earth's terrestrial ecosystems. Proceedings of the National Academy of Sciences USA. 2007; 104:12942-12945.

Hagerstrand T. A Monte Carlo approach to diffusion. European Journal of Sociology. 1965; 6:43-67.

Haken H, Portugali J. A synergetic approach to the self-organization of cities and settlements. Environment and Planning B. 1995; 22:35-46.

Heumann BW, Walsh SJ, McDaniel P. Assessing the application of a geographic niche-based model for crop suitability mapping in Northeast Thailand. Ecological Informatics. 2011; 6:257-269. [PubMed: 21860606] 
Heumann BW, Walsh SJ, Verdery A, Entwisle B, McDaniel PA, Rindfuss RR. Land use modeling using a geographic socio-economical niche-based approach: A case study from northeastern Thailand. Annals of the Association of American Geographers. 2013; 103:764-784.

Hudson, JC. Dissertation. Department of Geography, University of Iowa; Iowa City: 1967. Theoretical settlement geography.

Janssen MA, Walker BH, Langridge J, Abel N. An adaptive agent model for analysing co-evolution of management and policies in a complex rangeland system. Ecological Modelling. 2000; 131:249268.

Jones JW, Hoogenboom G, Porter CH, Boote KJ, Batchelor WD, Hunt LA, Wilkens PW, Singh U, Gijsman AJ, Ritchie JT. DSSAT cropping system model. European Journal of Agronomy. 2003; 18:235-265.

Kelley H, Evans T. The relative influences of land-owner and landscape heterogeneity in an agentbased model of land-use. Ecological Economics. 2011; 70:1075-1087.

Malanson GP. Considering complexity. Annals of the Association of American Geographers. 1999; 89:746-753.

Malanson GP, Butler DR, Walsh SJ. Chaos theory in physical geography. Physical Geography. 1990; 11:293-304.

Malanson GR, Zeng Y, Walsh SJ. Complexity at advancing ecotones and frontiers. Environment and Planning A. 2006a; 38:619-632.

Malanson GP, Zeng Y, Walsh SJ. Landscape frontiers, geography frontiers: lessons to be learned. Professional Geographer. 2006b; 58:383-396.

Manson SM. Simplifying complexity: a review of complexity theory. Geoforum. 2001; 32:405-414.

Manson SM. Agent-based modeling and genetic programming for modeling land change in the Southern Yucatan Peninsular Region of Mexico. Agriculture, Ecosystems and Environment. 2005; 111:47-62.

Manson SM. Bounded rationality in agent-based models: experiments with evolutionary programs. International Journal of Geographical Information Science. 2006; 20:991-1012.

Manson SM. Challenges in evaluating models of geographic complexity. Environment and Planning B. 2007; 34:245-260.

Manson SM, Evans T. Agent-based modeling of deforestation in southern Yucatan, Mexico, and reforestation in the Midwest United States. Proceedings of the National Academy of Sciences USA. 2077; 104:20678-20683.

Matthews R. The People and Landscape Model (PALM): Towards full integration of human decisionmaking and biophysical simulation models. Ecological Modelling. 2006; 194:329-343.

Matthews RB, Gilbert NG, Roach A, Polhill JG, Gotts NM. Agent-based land-use models: a review of applications. Landscape Ecology. 2007; 22:1447-1459.

Mena CF, Walsh SJ, Frizzelle BG, Malanson GP. Land use change of household farms in the Ecuadorian Amazon: design and implementation of an agent based model. Applied Geography. 2011; 31:210-222. [PubMed: 24436501]

Mialhe F, Becu N, Gunnell Y. An agent-based model for analyzing land use dynamics in response to farmer behaviour and environmental change in the Pampanga delta (Philippines). Agriculture, Ecosystems \& Environment. 2012; 161:55-69.

Moreno N, Quintero R, Ablan M, Barros R, Davila J, Ramirez H, Tonella G, Acevedo MF. Biocomplexity of deforestation in the Caparo tropical forest reserve in Venezuela: An integrated multi-agent and cellular automata model. Environmental Modeling \& Software. 2007; 22:664673.

Moss S, Pahl-Wostl C, Downing T. Agent-based integrated assessment modeling: the example of climate change. Integrated Assessment. 2001; 2:17-30.

Naivinit, Le Page, C.; Trebuil, G.; Gajaseni, N. Participatory agent-based modeling and simulation of rice production and labor migrations in Northeast Thailand. Environmental Modelling \& Software. 2010; 25:1345-1358.

Parker DC, Manson S, Janssen M, Hoffmann M, Deadman P. Multi-agent systems for the simulation of land use and land cover change: a review. Annals of the Association of American Geographers. 2003; 93:314-337. 
Parry M, Rosenzweig C, Livermore M. Climate change, and risk global food supply of hunger. Philosophical Transactions of the Royal Society B. 2005; 360:2125-2138.

Patt, A.; Siebenhuner, B. Agent based modeling and adaptation to climate change. In: Kemfert, C.; Praetorius, B., editors. Die okonomoschen Kosten des Klimwandels und der Klimpolitik. Deutsches Institute fur Wirtschaftsforschumg; Berlin: 2005. p. 310-320.

Phillips JD. Deterministic uncertainty in landscapes. Earth Surface Processes and Landforms. 1994; 19:389-401.

Piotrowski M. Migrant remittances and skipped generation households: investigating the exchange motive using evidence from Nang Rong, Thailand. Asian and Pacific Migration Journal. 2009; 18:163-196.

Piotrowski M, Tong Y. Economic and non-economic determinants of return migration: evidence from rural Thailand. Population. 2010; 65:361-377.

Pred AR, Kibel BM. An application of gaming simulation to a general model of economic locational processes. Economic Geography. 1970; 46:136-156.

Rigg JD. The role of the environment in limiting the adoption of new rice technology in northeastern Thailand. Transactions of the Institute of British Geographers. 1985; 10:481-494.

Rindfuss RR, Entwisle B, Walsh SJ, Mena CF, Erlien CM, Gray CL. Frontier land use change: synthesis, challenges, and next steps. Annals of the Association of American Geographers. 2007; 97:739-754.

Rindfuss RR, Piotrowski M, Entwisle B, Edmeades J, Faust K. Migrant remittances and the web of family obligations: Ongoing support among spatially extended kin in North-east Thailand, 1984-94. Population Studies. 2012; 66:87-104. [PubMed: 22272774]

Sengupta R, Lant C, Kraft S, Beaulieu J, Peterson W, Loftus T. Modeling enrollment in the Conservation Reserve Program by using agents within spatial decision support systems: an example from southern Illinois. Environment and Planning B. 2005; 32:821-834.

Schlueter M, Pahl-Wostl C. Mechanisms of resilience in common-pool resource management systems: an agent-based model of water use in a river basin. Ecology and Society. 2007; 12 \#4.

Tang W, Malanson GP, Entwisle B. Simulated village locations in Thailand using a multi-scale model including a neural network approach. Landscape Ecology. 2009; 24:557-575. [PubMed: 21399748]

VanWey LK. Land ownership as a determinant of temporary migration in Nang Rong, Thailand. European Journal of Population. 2003; 19:121-145.

Vongvisouk T, Mertz O, Thongmanivong S, Heinimann A, Phanvilay K. Shifting cultivation stability and change: Contrasting pathways of land use and livelihood change in Laos. Applied Geography. 2014; 46:1-10.

Walsh SJ, Crawford TW, Welsh WF, Crews-Meyer KA. A multiscale analysis of LULC and NDVI variation in Nang Rong District, Northeast Thailand. Agriculture, Ecosystems and Environment. 2001; 85:47-64.

Walsh SJ, Welsh WF, Evans TP, Entwisle B, Rindfuss RR. Scale dependent relationships between population and environment in Northeastern Thailand. Photogrammetric Engineering and Remote Sensing. 1999; 65:97-105.

Walsh SJ, Malanson GP, Entwisle B, Rindfuss RR, Mucha PJ, Heumann BW, McDaniel PM, Frizzelle BG, Verdery AM, Williams N, Xiaozheng Y, Ding D. Design of an Agent-Based Model to Examine Population-Environment Interactions in Nang Rong District, Thailand. Applied Geography. 2013; 39:183-198.

Walsh SJ, Messina JP, Mena CF, Malanson GP, Page PH. Complexity theory, spatial simulation models, and land use dynamics in the Northern Ecuadorian Amazon. Geoforum. 2008; 39:867878.

Welsh WF. Characterizing patterns of land degradation potential and agro-ecological sustainability in Nang Rong, Thailand. Photogrammetric Engineering and Remote Sensing. 2008; 74:765-773.

Ziervogel G, Bithell M, Washington R, Downing T. Agent-based social simulation: a method for assessing the impact of seasonal climate forecast applications among smallholder farmers. Agricultural Systems. 2005; 83:1-26. 


\section{Highlights}

We model endogenous land use dynamics as affected by exogenous climate change abstracted from surveys of villages in the Nang Rong district, Thailand.

An agent based model represents bounded rationality and balances economic drivers and demographic constraints.

Soil types underpin a crop growth model.

Villages tend to farm less land and reduce jasmine rice under extended drought or flooding.

Villages have individualized responses to climate change, indicative of path dependency. 


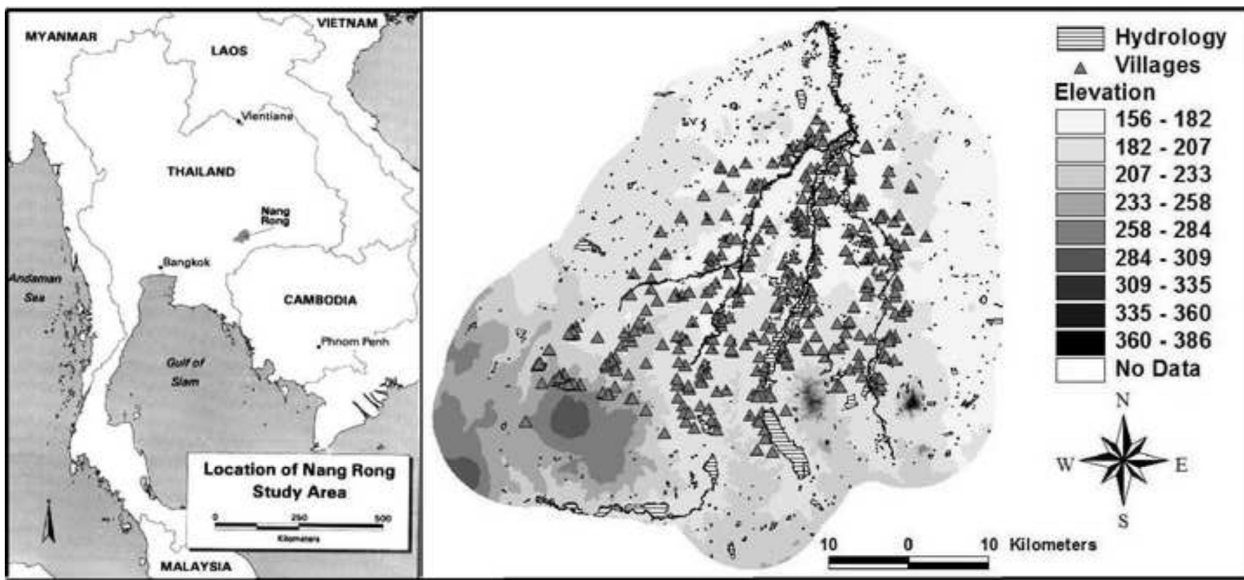

Figure 1.

Location of Nang Rong district. 

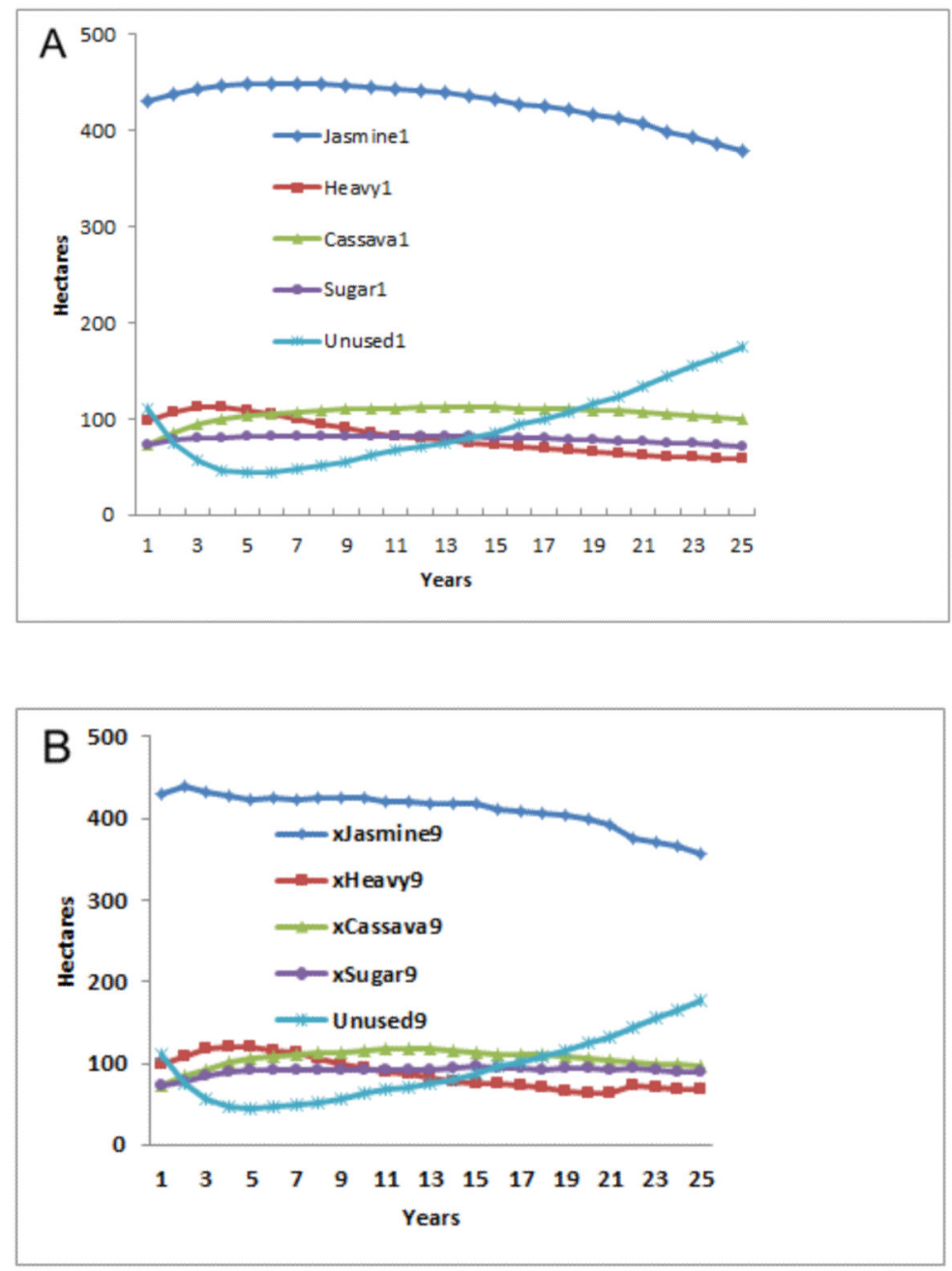

Figure 2.

Simulated land use (mean ha) for jasmine rice, heavy rice, cassava, and sugar cane for 41 virtual villages; a) simulated control climate, b) observed climate, 1975-2000. 

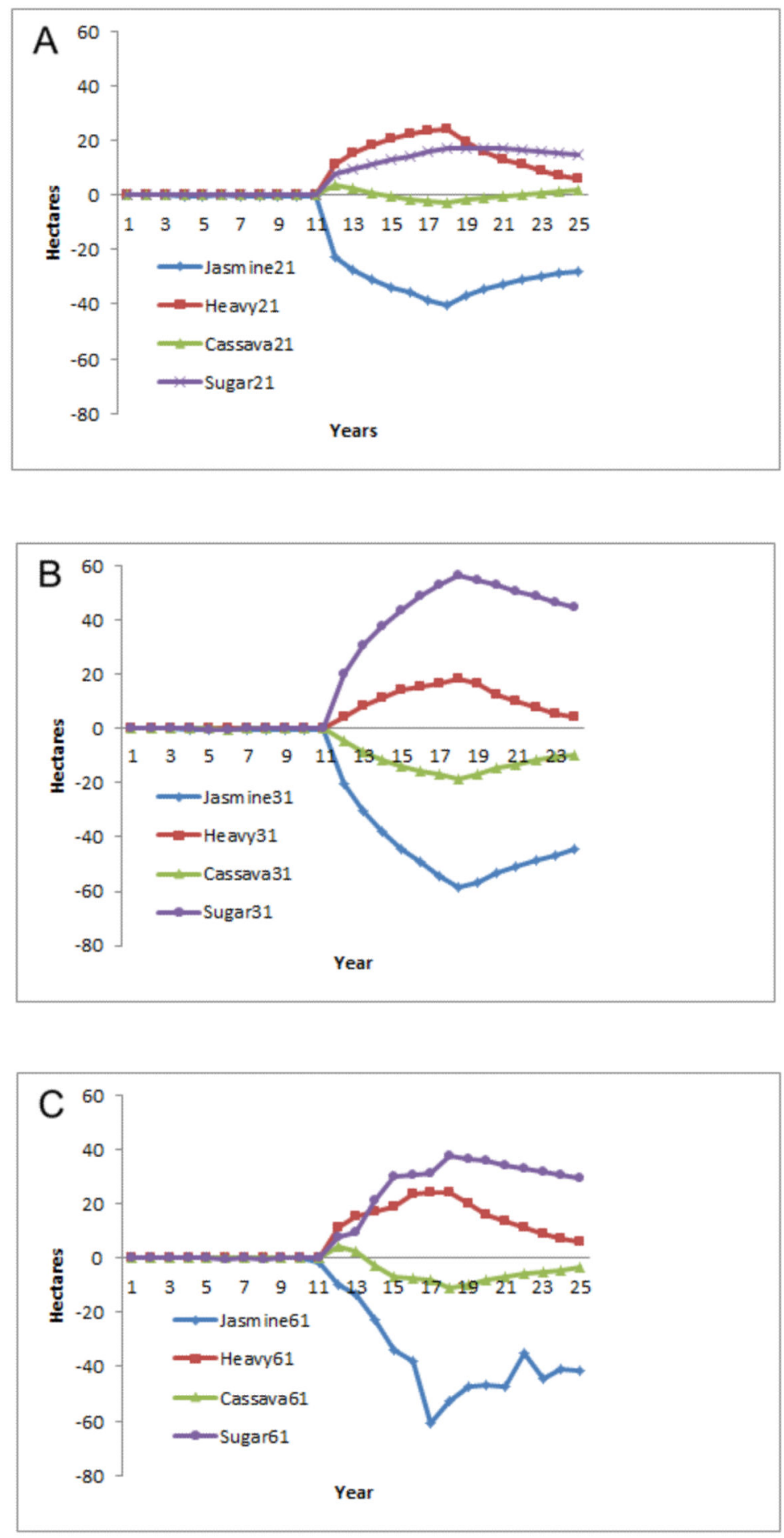

Figure 3.

Mean difference (Df) in area (ha) from the control climate for the villages in the climate scenarios for a) flood (C2, Crop21), b) drought (C3, Crop31), and c) extreme variability (C6, Crop61). 


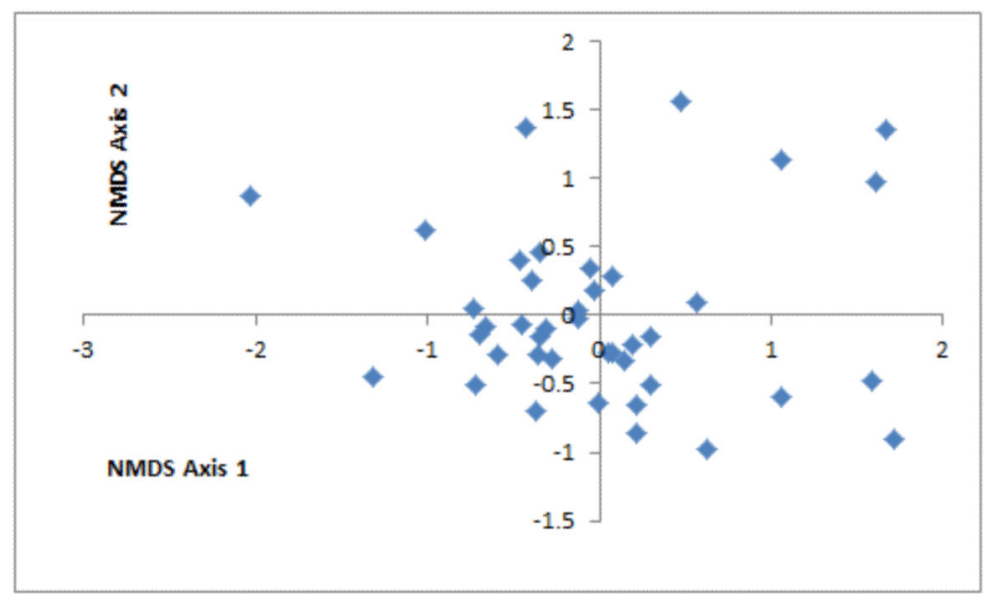

Figure 4.

Nonmetric multidimensional scaling of the villages based on the crop outcomes in extended drought (C3) for absolute area, difference from control climate, and difference from control climate relative to area farmed (Ab, Df, Rd). 


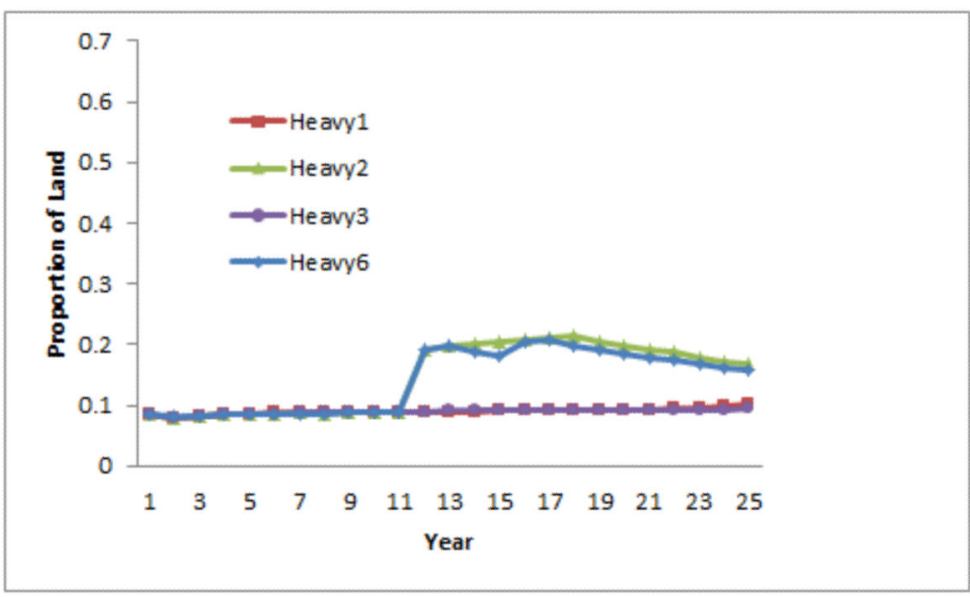

Figure 5.

Change in proportional area in jasmine rice for the control and extreme climate scenarios for village D. 


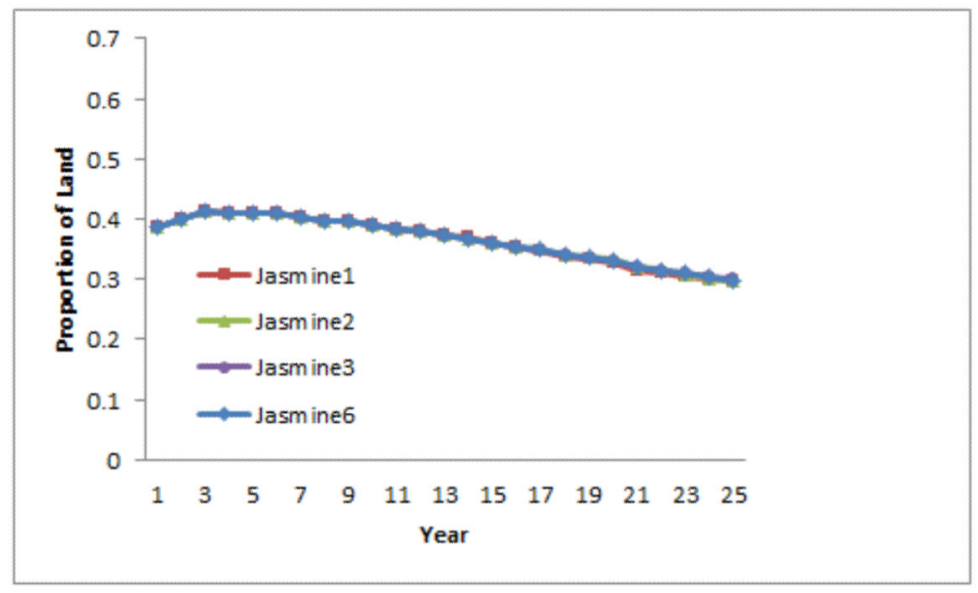

Figure 6.

Change in proportional area in cassava for the control and extreme climate scenarios for village $\mathrm{E}$. 


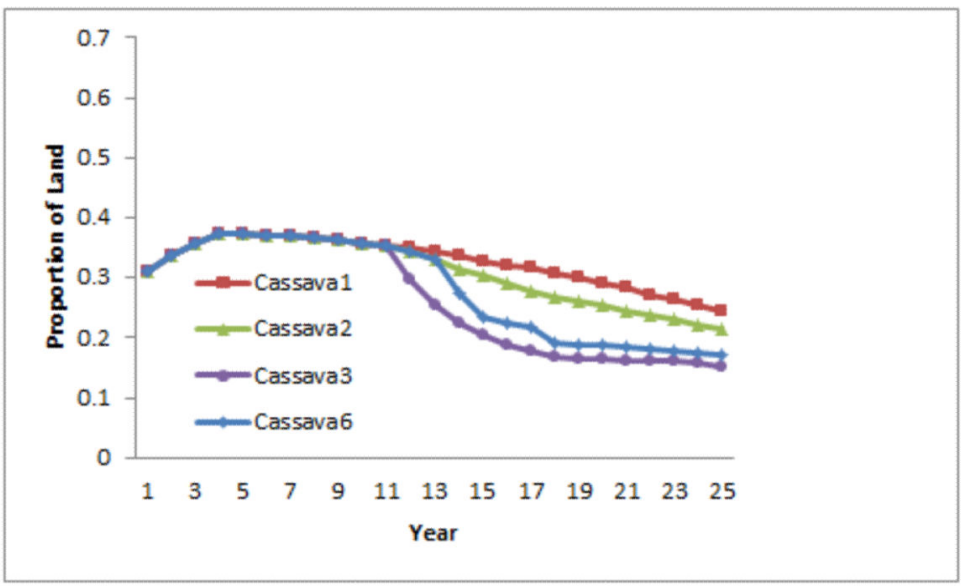

Figure 7.

Change in proportional area in heavy rice for the control and extreme climate scenarios for village $B$. 


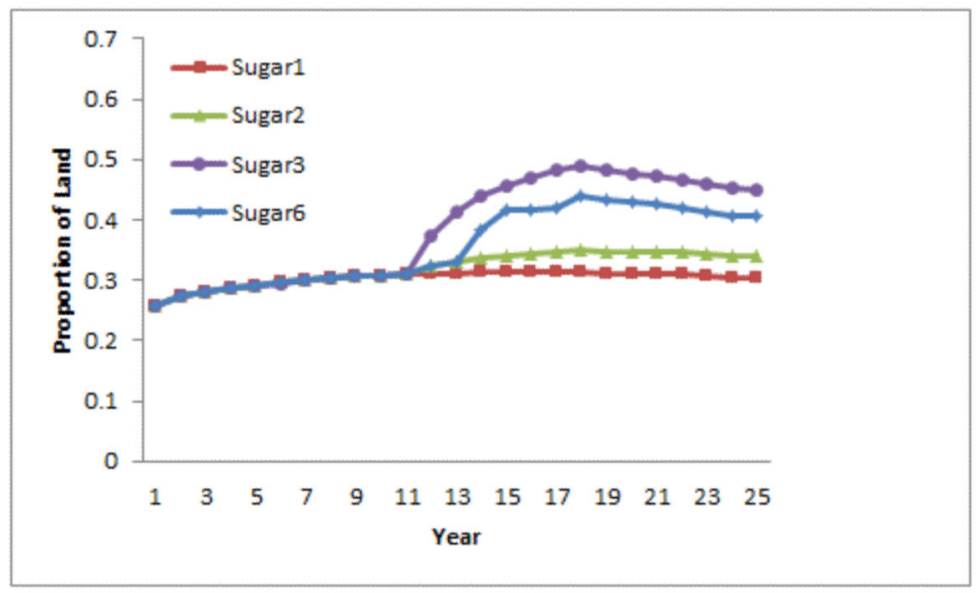

Figure 8.

Change in proportional area in land not in use by the village for the control and extreme climate scenarios for village $\mathrm{F}$. 


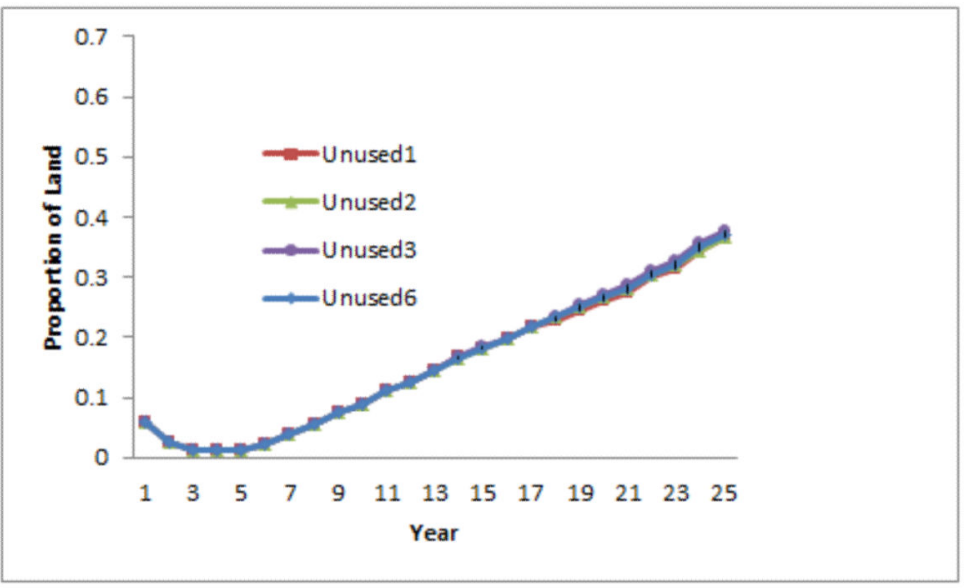

Figure 9.

Change in proportional area in cassava for the control and extreme climate scenarios for village A. 


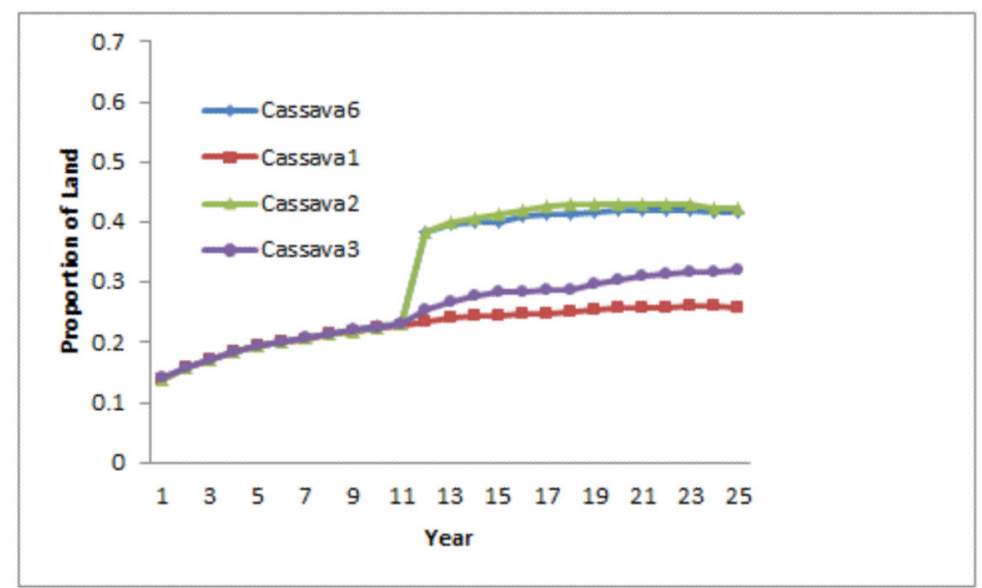

Figure 10.

Change in proportional area in jasmine rice for the control and extreme climate scenarios for village $\mathrm{A}$; note the scale change relative to figures above, while holding range the same. 


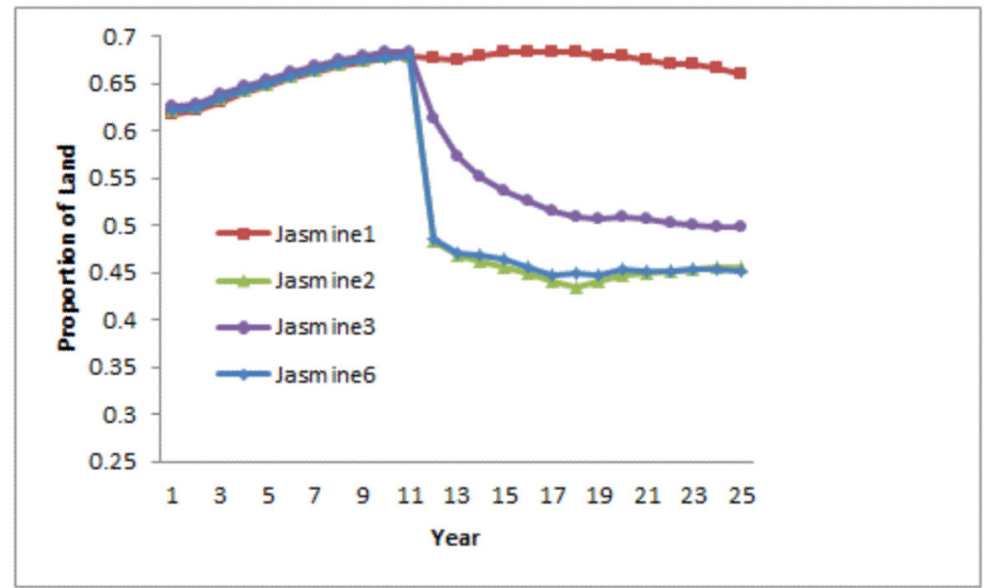

Figure 11.

Change in proportional area in jasmine rice for the control and extreme climate scenarios for village A. 


\section{Table 1}

Components of the agent based model that affect the land use decisions of households. The initial conditions of villages for these state variables are shown. Other factors that affect land use indirectly through migration are discussed by Entwisle et al. (2008a,b).

\begin{tabular}{cll}
\hline Village & mean & std dev \\
Households & 172 & 6.8 \\
Individuals & & \\
Child & 176 & 7.8 \\
Elderly & 103 & 3.9 \\
Adult non-Migrant & 403 & 16.8 \\
Adult Migrant & 223 & 9.1 \\
Assets (Baht) & 17682 & 887.7 \\
Land (ha) & 786 & 261 \\
\hline
\end{tabular}

Appl Geogr. Author manuscript; available in PMC 2015 September 01. 